\title{
Corrosion Prevention of the Generator Stator Hollow Copper Conductor and Water Quality Adjustment of Its Internal Cooling Water
}

\author{
Ling PAN ${ }^{1}$, Qianqian HAN ${ }^{1}$, Xuenong XIE ${ }^{2}$, Xuejun $\mathrm{XIE}^{1}$, Peng XIAO ${ }^{1}$ \\ ${ }^{1}$ School of Power and Mechanical Engineering, Wuhan University, Wuhan 430072, China \\ ${ }^{2}$ Sinohydro bureau 8 Co., LTD
}

\begin{abstract}
On the basis of expounding the corrosion mechanism of the stator hollow copper conductor in the water-cooling generator, methods of preventing corrosion of the stator hollow copper conductor in the water-cooling generator through adjusting water quality of its cooling water have been proposed. For internal water cooling systems which are airtight, the corrosion of the hollow copper conductor can be prevented through keeping foreign oxygen and carbon dioxide from entering the system, and the amount of oxygen in the internal water can be lowered by blowing high purity nitrogen. For systems not airtight, the corrosion of the hollow copper conductor can be inhibited through lowering the amount of oxygen to some extent by sealing and increasing $\mathrm{pH}$ value by processing part of cooling water with bypass small flow sodium-type mix-bed.
\end{abstract}

Keywords: generator, internal cooling-water, hollow copper conductor, corrosion and protection

\section{Corrosion Mechanism of the Generator Stator Hollow Copper Conductor}

The corrosion mechanism of the generator stator copper conductor has been studied by large quantities of researches home and abroad. The main reactions considered to take place in the process of copper corrosion are as follows:

1) Corrosion caused by dissolved oxygen:

Anodic reactions:

$$
\begin{aligned}
2 \mathrm{Cu}+\mathrm{H}_{2} \mathrm{O}-2 \mathrm{e} & \rightarrow \mathrm{Cu}_{2} \mathrm{O}+2 \mathrm{H}^{+} \\
\mathrm{Cu}-2 \mathrm{e} & \rightarrow \mathrm{Cu}^{2+} \\
\mathrm{Cu}-\mathrm{e} \rightarrow \mathrm{Cu}^{+} &
\end{aligned}
$$

Cathodic reactions:

$$
\begin{aligned}
& \mathrm{O}_{2}+2 \mathrm{H}_{2} \mathrm{O}+4 \mathrm{e} \rightarrow 4 \mathrm{OH}^{-} \\
& \mathrm{Cu}+2 \mathrm{OH}^{-} \rightarrow \mathrm{Cu}(\mathrm{OH})_{2} \\
& \mathrm{Cu}(\mathrm{OH})_{2} \rightarrow \mathrm{CuO}+\mathrm{H}_{2} \mathrm{O}
\end{aligned}
$$

Other cathodic reactions included:

$$
\begin{gathered}
2 \mathrm{Cu}^{+}+\mathrm{H}_{2} \mathrm{O}+2 \mathrm{e} \rightarrow \mathrm{Cu}_{2} \mathrm{O}+\mathrm{H}_{2} \\
\mathrm{Cu}^{+}+\mathrm{H}_{2} \mathrm{O}+\mathrm{e} \rightarrow \mathrm{CuO}+\mathrm{H}_{2} \\
2 \mathrm{Cu}^{+}+1 / 2 \mathrm{O}_{2}+2 \mathrm{e} \rightarrow \mathrm{Cu}_{2} \mathrm{O} \\
2 \mathrm{Cu}^{+}+\mathrm{O}_{2}+2 \mathrm{e} \rightarrow 2 \mathrm{CuO}
\end{gathered}
$$

The result is the corrosion of copper and the formation of an oxidative membrane (the copper oxidative protection membrane) with double-layer structure on the surface of the copper at the meantime in normal case.

2) In acidic environment, the copper oxidative protection membrane will be dissolved. The internal cooling water which contains carbon dioxide belongs to acidic medium as the dissolved carbon dioxide can react as the following reaction.

$$
\begin{aligned}
& \mathrm{CO}_{2}+2 \mathrm{H}^{+}=\mathrm{Cu}^{2+}+\mathrm{H}_{2} \mathrm{O} \\
& \mathrm{H}_{2} \mathrm{CO}_{3} \rightleftharpoons \mathrm{H}^{+}+\mathrm{HCO}_{3}^{-}
\end{aligned}
$$

Furthermore, $\mathrm{pH}$ value will decrease under the condition of existence of carbon dioxide due to the high purity and poor buffering performance of internal cooling water. 
For example, $\mathrm{pH}$ value of the pure water will be lower than 6.7 when there is $1 \mathrm{mg} / \mathrm{L}$ dissociate carbon dioxide.

Therefore, the corrosion is accelerated by carbon dioxide, mainly through lowering $\mathrm{pH}$ value of internal cooling water and the following reactions which can destroy the protective membrane on the surface.

$$
\begin{gathered}
\mathrm{CuO}+2 \mathrm{H}^{+}=\mathrm{Cu}^{2+}+\mathrm{H}_{2} \mathrm{O} \\
\mathrm{Cu}_{2} \mathrm{O}+2 \mathrm{H}^{+}=2 \mathrm{Cu}^{+}+\mathrm{H}_{2} \mathrm{O} \\
\mathrm{Cu}(\mathrm{OH})_{2}+2 \mathrm{H}^{+}=\mathrm{Cu}^{2+}+2 \mathrm{H}_{2} \mathrm{O}
\end{gathered}
$$

\section{Methods of Preventing the Corrosion of the Generator Stator Copper Conductor}

At present, many scientific workers home and abroad are carrying out a lot of researches on the problem of copper conductor corrosion and protection, trying to seek for a method which is more economical, convenient, safe and reliable to prevent the corrosion of hollow copper conductor.

\subsection{Lower the Amount of Dissolved Oxygen and Carbon Dioxide in the Internal Cooling Water}

The corrosion rate peaks in common case when the concentration of dissolved oxygen ranges from $0.5 \mathrm{mg} / \mathrm{L}$ to $2.0 \mathrm{mg} / \mathrm{L}$. The concentration of dissolved oxygen in the water contacting with air at the temperature of $25^{\circ} \mathrm{C}$ is
$1.4 \sim 3.2 \mathrm{mg} / \mathrm{L}$. The operational temperature of cooling water ranges from $20^{\circ} \mathrm{C}$ to $85^{\circ} \mathrm{C}$, and the temperature of water flowing through hollow copper conductor is usually above $40^{\circ} \mathrm{C}$. The amount of oxygen decreases when the temperature increases, but the decreased extent of the amount of oxygen is not large.

For the purpose of studying the effect dissolved oxygen had on the copper corrosion, the operational environment of internal cooling water was simulated and the relationship between dissolved oxygen amount and corrosion behavior of copper at $50^{\circ} \mathrm{C}$ was investigated. The result of experiment carried out to study the relationship between oxygen concentration and copper corrosion at $50^{\circ} \mathrm{C}$ in simulated internal cooling water operational environment is shown in Table 1 . The test was conducted using pure copper specimen as test material and deionized water as test medium at the temperature of $50 \pm 1^{\circ} \mathrm{C}$ and the test time was $72 \mathrm{~h}$. The concentration of dissolved oxygen was controlled through blowing nitrogen into the water during the test. Pre-test $\mathrm{pH}$ value and conductivity is measured at $11^{\circ} \mathrm{C}$ before starting to blow nitrogen. It can be learned from Table 1 that the corrosion of copper in deionized water can be inhibited effectively when the concentration of dissolved oxygen is controlled ap-

\begin{tabular}{|c|c|c|c|c|c|c|}
\hline \multirow[b]{2}{*}{$\begin{array}{l}\text { Dissolved Oxygen } \\
\text { Content, } \mu \mathrm{g} / \mathrm{L}\end{array}$} & \multicolumn{2}{|c|}{ Pre-test } & \multicolumn{4}{|c|}{ After test } \\
\hline & $\begin{array}{c}\text { Conductivity, } \\
\mu \mathrm{s} / \mathrm{cm}\end{array}$ & $\mathrm{pH}$ & $\begin{array}{c}\text { Conductivity, } \\
\mu \mathrm{s} / \mathrm{cm}\end{array}$ & $\mathrm{pH}$ & $\begin{array}{c}\mathrm{Cu}^{2+} \text { content, } \\
\mu \mathrm{g} / \mathrm{L}\end{array}$ & $\begin{array}{l}\text { Surface condition of } \\
\text { test specimen }\end{array}$ \\
\hline Below 5 & 0.64 & 6.2 & 1.85 & 7.15 & 3.9 & bright \\
\hline $8 \sim 12$ & 0.65 & 6.2 & 2.12 & 7.20 & 8.9 & bright \\
\hline $40 \sim 60$ & 0.67 & 6.2 & 2.10 & 7.15 & 45.1 & light dead red \\
\hline $90 \sim 110$ & 0.65 & 6.2 & 2.43 & 7.14 & 103.7 & partially black \\
\hline $450 \sim 550$ & 0.64 & 6.2 & 2.38 & 7.00 & 300.8 & partially black \\
\hline $950 \sim 1050$ & 0.65 & 6.2 & 3.05 & 6.90 & 269.2 & partially black \\
\hline $4800 \sim 5200$ & 0.65 & 6.2 & 2.30 & 6.75 & 190.4 & mostly black \\
\hline 11500 & 0.65 & 6.2 & 1.92 & 6.80 & 182.2 & dark dead red \\
\hline
\end{tabular}
proximately at the level of $10 \mu \mathrm{g} / \mathrm{L}$.

Table 1. Result of test on the relationship between dissolved oxygen concentration and copper corrosion at the temperature of $50{ }^{\circ} \mathrm{C}$ 
For a 300MW water-hydrogen-hydrogen cooled unit with airtight internal water cooling systems and an internal cooling water tank whose volume is $2 \mathrm{~m}^{3}$, the conductivity and $\mathrm{pH}$ value of the internal cooling water is monitored continuously at the sample flow ranges from $500 \mathrm{ml} / \mathrm{min}$ to $700 \mathrm{ml} / \mathrm{min}$. Thus, the amount of daily make-up water, which is the effluent of high-speed mixed bed, is $0.72 \mathrm{t}$. The effluent water quality of high-speed mixed bed is that the conductivity is no more than $0.2 \mu \mathrm{s} / \mathrm{cm}$, and $\mathrm{pH}$ value ranges from 7.03 to 7.10 , and the concentration of dissolved oxygen is $20 \sim 30 \mu \mathrm{g} / \mathrm{L}$, and there is no $\mathrm{NH}_{4}^{+}$. As a result, the operation of internal cooling system is in good condition and the corrosion of hollow copper conductor is inhibited significantly, as the internal cooling water has conductivity no more than $0.2 \mu \mathrm{s} / \mathrm{cm}, \mathrm{pH}$ value ranging from 7.03 7.10, and low copper concentration which is $9.85 \sim 16.4 \mu \mathrm{g} / \mathrm{L}$ [2].

For a $500 \mathrm{MW}$ supercritical pressure unit using condensate whose $\mathrm{pH}$ value is 8.6 8.8 approximately as make-up of the internal cooling water, due to the continuous dissolving of carbon dioxide, $\mathrm{pH}$ value of the internal cooling water is above 8.2 in common case, and the conductivity of $1.5 \sim 3.0 \mu \mathrm{s} / \mathrm{cm}$ is relatively high [3]. After blowing high purity nitrogen into the internal cooling water, $\mathrm{pH}$ value of the internal cooling water is above 8.0 , and the concentration of copper is lowered to less than $10 \mu \mathrm{g} / \mathrm{L}$, and the conductivity can be below $1.0 \mu \mathrm{s} / \mathrm{cm}$.

\section{2 pH Adjustment for Preventing Corrosion of Hollow Copper Conductor}

Figure 1 is the reduced potential-pH diagram of copper-water system, which is ploted taking $\mathrm{Cu} 、 \mathrm{Cu}_{2} \mathrm{O} 、 \mathrm{CuO}$ and $\mathrm{Cu}_{2} \mathrm{O}_{3}$ as the balanced solid-phases and the value of balanced concentration of $\mathrm{Cu}^{2+}$ and other relative ions at the level of $10^{-6} \mathrm{~mol} / \mathrm{L}$ (i.e. $64 \mu \mathrm{g} / \mathrm{L}$ ) or $10^{-6.2} \mathrm{~mol} / \mathrm{L}$ (i.e. $40 \mu \mathrm{g} / \mathrm{L}$ ) as the threshold concentration which can indicate weather the copper is corrupted or not [1][4].

It can be learned from Figure 1 that the balanced potential-pH diagram of copper-water system is divided into three parts by the isoline of solubility of $10^{-6} \mathrm{~mol} / \mathrm{L}$ or $10^{-6.2} \mathrm{~mol} / \mathrm{L}$ for copper and its oxides: corrosion region, no-corrosion region and passivation region. The state of copper, in another word, which region the copper falls into, is jointly determined by the potential of copper-water system and its $\mathrm{pH}$ value. As the potential of hollow copper conductor in the internal cooling water system is difficult to measure, the $\mathrm{pH}$ interval where copper and its oxides can exist stably is 6.94 to 10.81 or 7.04 to 10.31 when $10^{-6} \mathrm{~mol} / \mathrm{L}$ (i.e. $64 \mu \mathrm{g} / \mathrm{L}$ ) or $10^{-6.2} \mathrm{~mol} / \mathrm{L}$ (i.e. $40 \mu \mathrm{g} / \mathrm{L}$ ) is taken as the threshold concentration which indicates the copper is corrupted weather or not.

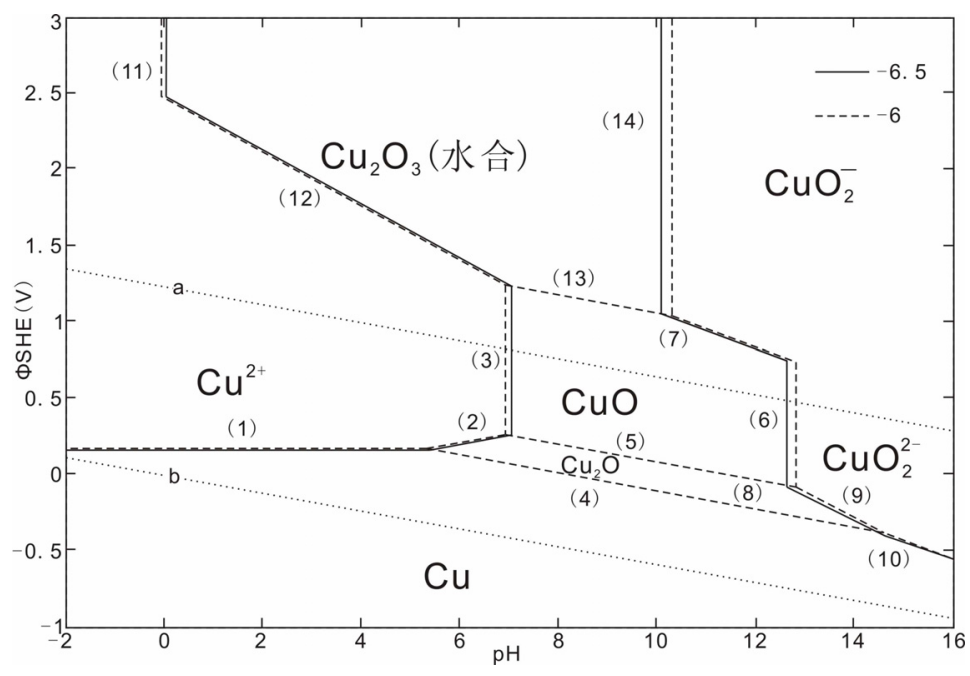

Figure 1. Potential-pH diagram for copper-water system 
It can be learned through calculation that the conductivity of newly-prepared deionized water is $2.1 \mu \mathrm{s} / \mathrm{cm}$ when its $\mathrm{pH}$ value is adjusted to 8.9 using analytically pure ammonia water, and is $2.48 \mu \mathrm{s} / \mathrm{cm}$ when its $\mathrm{pH}$ value is adjusted to 9 using analytically pure sodium hydroxide solution. In view of the requirement of the conductivity no more than $2 \mu \mathrm{s} / \mathrm{cm}$ in the currently standard for internal cooling water quality, $\mathrm{pH}$ value of internal cooling water is controlled between 7 and 8.9, and the corrosion of hollow copper conductor can be inhibited significantly. It is true in the practical internal cooling water system. Among the various methods which can be employed to increase $\mathrm{pH}$ value, the safest and most reliable one is processing part of cooling water with bypass small flow sodium-type mix-bed. When part of internal cooling water flows through the sodium-type small mix-bed, the cations such as the small amount of $\mathrm{Cu}^{2+}$ and $\mathrm{Fe}^{3+}$ are converted into $\mathrm{Na}^{+}$and the anions are converted into $\mathrm{OH}^{-}$before mixing with the rest internal cooling water which does not pass through the Sodium-type small mix-bed. Thus, it corresponds to adding approximately pure sodium hydroxide to the internal cooling water. $\mathrm{PH}$ value of internal cooling water can be adjusted to be 7 8.9 as long as there is trace amount of impurity ions such as iron and copper existing in the internal cooling water.

For a 300MW water-hydrogen-hydrogen cooled unit using deionized water as make-up water, the internal cooling water is processed by small sodium-type mixbed, whose ratio of cation resin and anion resin is $2.7: 1$. Its water quality is as follows: The conductivity is below $0.5 \mu \mathrm{s} / \mathrm{cm}$, hardness is $0, \mathrm{pH}$ is between 7 and 8 , and the concentration of copper is below $10 \mu \mathrm{g} / \mathrm{L}$ [5].

\section{Conclusions}

1) The corrosion of generator stator hollow copper conductor is caused by oxygen and accelerated by carbon dioxide.

2) For internal water cooling systems which are airtight, the corrosion of the hollow copper conductor can be prevented through keeping foreign oxygen and carbon dioxide from entering the system, and the amount of oxygen in the internal water can be lowered by blowing high purity nitrogen.

3) For systems not airtight, the corrosion of the hollow copper conductor can be inhibited through lowering the amount of oxygen to some extent by sealing and increasing $\mathrm{pH}$ value by processing part of cooling water with bypass small flow sodium-type mix-bed.

Of course, not only hollow copper conductor can be prevented from corrosion, but also the internal cooling water quality can be adjusted better when the internal water cooling systems are airtight, and $\mathrm{pH}$ of the cooling water is increased by processing part of cooling water with bypass small flow sodium-type mix-bed.

\section{REFERENCES}

[1] Gong Xunjie, "The corrosion and protection of the thermal equipment," The Chinese Electrical Power Press, Beijing, 1998.

[2] Zhang Enkui, "The cause of generator's inner cooling water-quality worsening in Shuangliao power plant and corresponding treatment," Jilin Electric Power Technology, Vol. 1, pp. 40-41, 2000.

[3] Zhang Jianli and Li Baoguo, "The optimization of the inner cooling-water of the generator's stator," North-China Electric Power Technology, Vol. 4, pp. 1-3, 2003.

[4] Xie xuejun, Pan Ling, et al., "Potential-pH chart for copper-water system and controlling $\mathrm{pH}$ of internal cooling water of generator to prevent corrosion," Corrosion Science and Protection Technology, Vol. 19, No. 3, 2007.

[5] He Shaohong, "Studies on tubular copper conductor corrosion of the inner-cooling water system and corresponding protection," Sichuan Electric Power Technology, Vol. 6, pp. 6-8, 2000. 